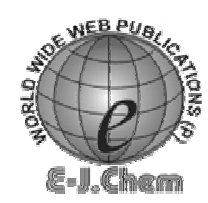

http://www.e-journals.net
ISSN: 0973-4945; CODEN ECJHAO

E-Journal of Chemistry

Vol. 5, No.2, pp.275-280, April 2008

\title{
Corrosion Inhibition of Mild Steel in Hydrochloric Acid by Sodium Lauryl Sulfate (SLS)
}

\author{
ATUL KUMAR \\ Department of Applied Sciences and Humanities, \\ N.C. College of Engineering, Israna-132107 (Panipat) \\ atul_verma1234@rediffmail.com; Phone+919416311565
}

Received 18 September 2007; Accepted 10 November 2007

\begin{abstract}
Effect of Sodium Lauryl Sulfate (SLS), a surfactant on corrosion of mild steel in $1 \mathrm{M}$ hydrochloric acid was studied using three techniques namely: weight loss, electrochemical polarization and metallurgical research microscopy. Results obtained reveal that SLS is good inhibitor and shows very good corrosion inhibition efficiency (IE). The IE was found to vary with concentration of inhibitor and temperature. The electrochemical polarization result revealed that SLS is anodic in nature.
\end{abstract}

Keywords: Corrosion Inhibition, Mild steel, Electrochemical polarization.

\section{Introduction}

Corrosion of metals generally occurs in the presence of oxygen and moisture and involves two electrochemical reactions. Oxidation occurs at anodic site and reduction occurs at cathodic site. In acidic medium hydrogen evolution reaction predominates. Inhibitors are generally used to protect materials against deterioration from corrosion. Most of the well-known acid inhibitors used in industry are organic compounds having multiple bonds in their molecules that mainly contain nitrogen, sulphur, oxygen atoms through which they get adsorbed on the metal surface ${ }^{1-5}$. The effect of temperature on the inhibiting process is of great importance in industry. Effective inhibitors are expected to perform under a wide range of conditions. M.A. Quaraishi et $a l^{6}$ reported the use of four triazoles namely, 4-amino- 3 methyl -5 mercapto $-1,2,4$ triazole (AMMT), 4-amino- 3 ethyl -5 mercapto $-1,2,4$ triazole (AEMT), 4-amino- 3 propyl -5 mercapto $-1,2,4$ triazole (APMT) and 4 -amino- 3 butyl -5 mercapto $-1,2,4$ triazole (ABMT) as inhibitors for the corrosion of mild steel in aqueous solution containing $20 \%$ formic acid and $20 \%$ acetic acid. The use of surfactants has been studied and it was shown that the inhibition efficiency increases with the no. of carbon atoms in the molecule. These compounds show very good inhibition efficiency near their critical micelle concentration ${ }^{7-10}$. The inhibitor adsorption mode was strictly dependent on the inhibitor structure ${ }^{7,11}$. Z. Ait Chikh and coworkers ${ }^{12}$ studied the effect of 1,12- bis (1,2,4-triazolyl) dodecane on carbon steel in $1 \mathrm{M} \mathrm{HCl}$ solution by using electrochemical and analytical techniques.In the present paper, study of the inhibiting effect of SLS on mild steel surface in aggressive $1 \mathrm{M} \mathrm{HCl}$ solution is presented. 


\section{Experimental}

Electrolyte

For the preparation of aggressive $\mathrm{HCl}$ solution AR grade(Aldrich) $\mathrm{HCl}$ was used. Approximate concentrations of acid were prepared using double distilled water. Inhibitor concentrations ranging from 50 to $250 \mathrm{ppm}$ in $1 \mathrm{M} \mathrm{HCl}$ solution were prepared.

\section{Specimens}

Mild Steel specimens of chemical composition C-0.14, Si-0.03, Mn-0.32, S-0.05, P-0.2, Ni$0.01, \mathrm{Cu}-0.01, \mathrm{Cr}-0.01$ and Fe-Balance (wt \%) were used. The specimens were mechanically polished with emery papers of 150, 320 and 600 grade, degreased with acetone, washed in double distilled water and finally dried. The cleaned specimens were weighed before and after immersion in $1 \mathrm{M} \mathrm{HCl}$ for $24 \mathrm{~h}$ in the absence and presence of various concentrations of SLS at different temperatures in the range of $25-45^{\circ} \mathrm{C}$.

\section{Weight loss measurements}

The mild steel strips of size $(3.0 \times 1.5 \times 0.0025) \mathrm{cm}$ were used for weight loss measurements. Weight loss measurements were carried out at different temperatures in the range $25-45^{\circ} \mathrm{C}$ for $24 \mathrm{~h}$ in $1 \mathrm{M} \mathrm{HCl}$ solutions. The specimens were weighed before and after immersion and the percentage inhibition efficiency (1E) was calculated using the following equation.

$$
\mathrm{IE}=\frac{(\mathrm{Wo}-\mathrm{W})}{\mathrm{W}} \times 100
$$

Where $\mathrm{w}_{\mathrm{o}}$ and $\mathrm{w}$ are the weight loss in absence and presence of the inhibitor respectively.

\section{Electrochemical polarization measurements}

For electrochemical polarization studies mild steel strips of same composition and coated with commercially available lacquer with exposed area of $1.0 \mathrm{~cm}^{2}$ were used and experiments were carried out at temperature $35 \pm 1{ }^{\circ} \mathrm{C}$. The electrochemical measurements were carried out in a conventional three-electrode cell. The working electrode was a mild steel specimen of $1 \mathrm{~cm}^{2}$ area. A saturated calomel electrode (SCE) and a platinum foil were used as the reference and auxiliary electrodes respectively. The temperature was controlled thermostatically at $35 \pm 1{ }^{\circ} \mathrm{C}$. Equilibrium time leading to steady state of the specimens was $30 \mathrm{~min}$. Electro chemical polarization studies were carried out using a potentiostat / galvanostat PGS 20IT (Radiometer Analytical SA).

Corrosion rate $(\mathrm{CR})$ was calculated using the following formula.

$$
\mathrm{CR}=\frac{0.13 \times \mathrm{I}_{\text {corr }} \times \mathrm{EW}}{\mathrm{D}}
$$

where $\mathrm{I}_{\text {corr }}=$ Corrosion current density in $\mathrm{mA} / \mathrm{cm}^{2}$.

$\mathrm{EW}=$ Equivalent weight of the metal in $\mathrm{g} / \mathrm{eq}$.

$\mathrm{D}=$ Density of metal in $\mathrm{g} / \mathrm{cm}^{3}$.

\section{Metallurgical research microscopy technique}

To study the morphology of corroded surface of the specimen after exposing it to $1 \mathrm{M} \mathrm{HCl}$ in the absence and presence of various concentrations of SLS at various temperatures range $\left(25{ }^{\circ} \mathrm{C}\right.$ to $\left.45{ }^{\circ} \mathrm{C}\right)$ micrographs were taken through Metallurgical research microscope (JSM840 JEOL). All micrographs were taken at magnification of $\mathrm{x} 400$.

\section{Results and Discussions}

\section{Weight loss studies}

The corrosion inhibition efficiencies (IE) of SLS systems obtained from weight loss data are given in Table 1. It is seen that SLS inhibit corrosion of mild steel in $1 \mathrm{M} \mathrm{HCl}$ acid at all 
concentrations under study. It has been observed that IE for SLS increases with the increase in Concentration as shown in Figure 1. The influence of temperature on IE of SLS at various concentrations is shown in Figure 2. The IE increases with temperature up to $35^{\circ} \mathrm{C}$ and after that it decreases at higher temperature due to desorption of inhibitor.

Table 1. Inhibition efficiencies (IE) obtained from weight loss data in $1 \mathrm{M} \mathrm{HCl}$ solution in presence and absence of Sodium Lauryl Sulfate (SLS) at different temperatures.

\begin{tabular}{cccc}
\hline Temperature, ${ }^{\circ} \mathrm{C}$ & Concentration of SLS, ppm & Corrosion rate, mpy & IE, \% \\
\hline 25 & ZERO & 206.65 & Blank \\
25 & 50 & 146.54 & 29.08 \\
25 & 100 & 142.08 & 31.24 \\
25 & 150 & 138.85 & 32.81 \\
25 & 200 & 132.37 & 35.94 \\
25 & 250 & 100.80 & 51.22 \\
35 & ZERO & 606.80 & Blank \\
35 & 50 & 275.26 & 54.64 \\
35 & 100 & 242.88 & 59.97 \\
35 & 150 & 210.90 & 65.24 \\
35 & 200 & 171.63 & 71.71 \\
35 & 250 & 160.30 & 73.58 \\
45 & ZERO & 1755.82 & Blank \\
45 & 50 & 1668.59 & 4.97 \\
45 & 100 & 1664.13 & 5.22 \\
45 & 150 & 1605.44 & 8.56 \\
45 & 200 & 1022.12 & 41.78 \\
45 & 250 & 948.45 & 45.98 \\
\hline
\end{tabular}

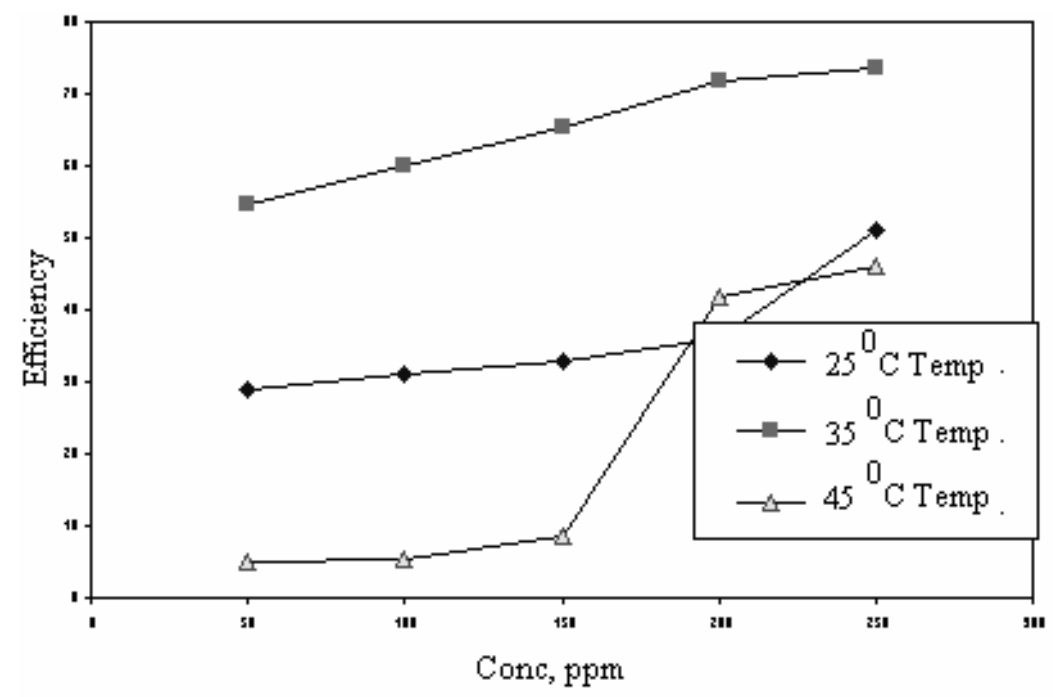

Figure 1. Variation of percentage inhibition efficiency with SLS concentration. 


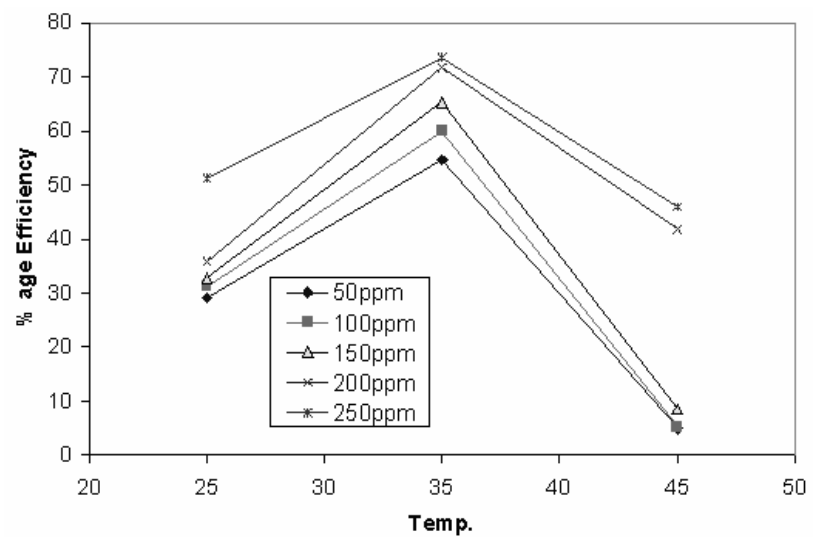

Figure 2. Variation of percentage inhibition efficiency of SLS with solution temperature.

Electrochemical polarization measurements

Figure 3 shows the polarization curves in $1 \mathrm{M} \mathrm{HCl}$ solutions with and without addition of SLS at different concentrations. The corrosion current density decreases with increasing inhibitor concentrations and the corrosion potential shifts depending on the inhibitor concentration. The values of the electrochemical parameters obtained from the polarization curves, namely: corrosion potential $\left(E_{\text {corr }}\right)$, cathodic Tafel slope $\left(\beta_{c}\right)$, anodic Tafel slope $\left(\beta_{\mathrm{a}}\right)$, corrosion current density $\left(\mathrm{I}_{\text {corr }}\right)$, resistance polarization $(\mathrm{Rp})$ and \%age inhibition efficiency (\% I.E.) for the different concentrations of CPC and SLS are given in Table 2. The inhibition efficiency in each case was calculated according to the following equation.

$$
\operatorname{IE}(\%)=\left(1-\mathrm{I}_{\text {corr }} / \mathrm{I}_{\text {corr }}\right) \times 100
$$

Where $\mathrm{I}_{\text {corr }}$ and I' ${ }_{\text {Corr }}$ are the corrosion current density in the absence and in the presence of inhibitor respectively.

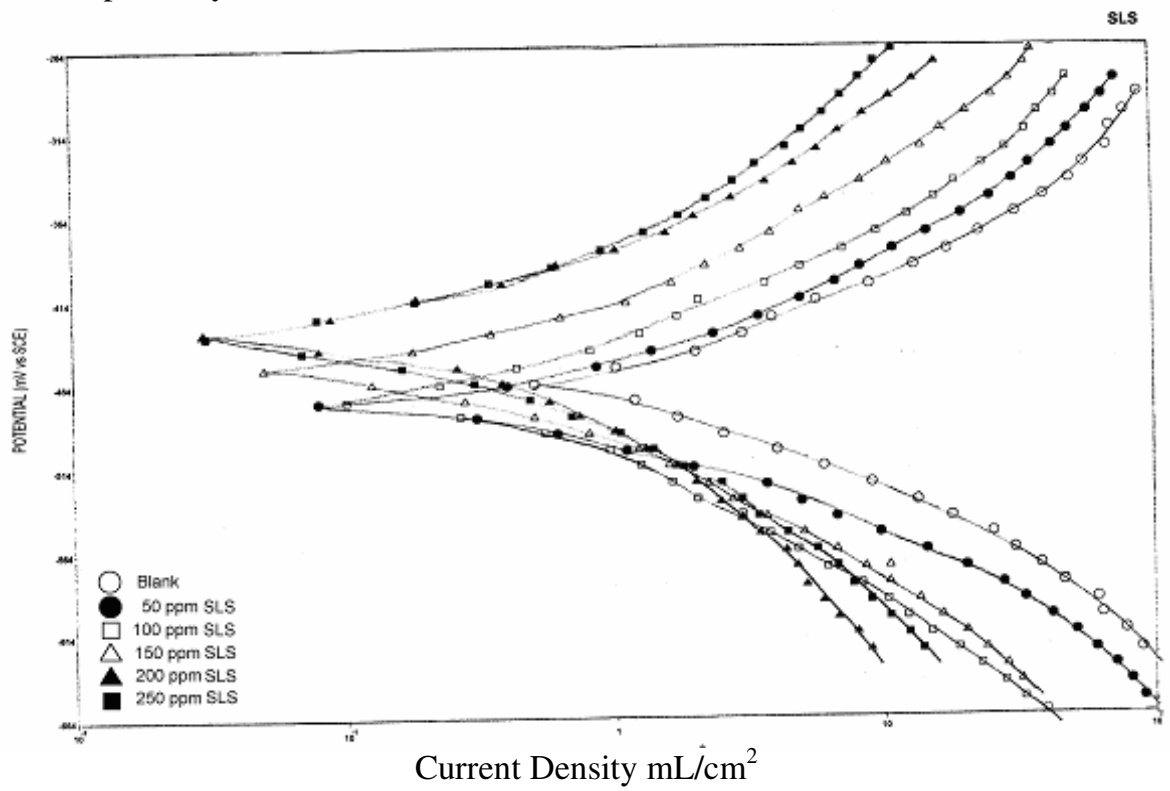

Figure 3 Polarization curves of mild steel in $1 \mathrm{M} \mathrm{HCl}$ in absence and presence of various concentrations of SLS. 
Table 2. Electrochemical parameters of mild steel corrosion in $1 \mathrm{M} \mathrm{HCl}$ solution contain various concentrations of Sodium Lauryl Sulfate (SLS) at $35^{\circ} \mathrm{C}$.

\begin{tabular}{ccccccc}
\hline $\begin{array}{c}\text { Concentration } \\
\text { ppm }\end{array}$ & $\begin{array}{c}\text { E corr } \\
\mathrm{mV}\end{array}$ & $\begin{array}{c}\beta \mathrm{\beta amv} / \\
\text { decades }\end{array}$ & $\begin{array}{c}\beta \mathrm{cmv} / \\
\text { decades }\end{array}$ & $\begin{array}{c}\text { I.corr. } \\
\mu \mathrm{A} / \mathrm{cm}^{2}\end{array}$ & $\begin{array}{c}\text { Corrosion } \\
\text { Rate, mpy }\end{array}$ & IE, \% \\
\hline Blank & -464 & 1.95 & 2.48 & 1300 & 600.51 & Blank \\
50 & -475 & 11.11 & 2.89 & 0.560 & 258.68 & 56.92 \\
100 & -475 & 4.75 & 7.84 & 0.500 & 235.58 & 60.77 \\
150 & -455 & 11.76 & 5.56 & 0.140 & 189.39 & 68.46 \\
200 & -439 & 9.52 & 20.00 & 0.350 & 161.68 & 73.08 \\
250 & -436 & 19.05 & 11.63 & 0.340 & 157.06 & 73.85 \\
\hline
\end{tabular}

The results depicted in Table 2 shows a decrease of the corrosion current density with the increasing SLS concentrations. The addition of SLS also leads to change in cathodic and anodic Tafel slopes. The corrosion potential is found to shift to more positive potential with increase in inhibitor concentration in presence of both the inhibitors. Thus the corrosion inhibition of mild steel in $1 \mathrm{M} \mathrm{HCl}$ solutions is predominantly under anodic control. The inhibition efficiency is found to reach to a maximum value at $250 \mathrm{ppm}$ inhibitor concentrations. The maximum values attained is $74 \%$ in $1 \mathrm{M} \mathrm{HCl}$ solutions in presence of $250 \mathrm{ppm}$ concentrations of SLS at $35^{\circ} \mathrm{C}$.

\section{Metallurgical research microscopy}

In order to evaluate the conditions of the mild steel surfaces in contact with $1 \mathrm{M} \mathrm{HCl}$ solutions, a superficial analysis was carried out. The micrographs of the specimens in presence of $1 \mathrm{M}$ $\mathrm{HCl}$ solutions are shown in Fig.4 (a). The influence of the SLS addition (250ppm) separately on the mild steel in Figs 4(b). It can be calculated from the figures that pitting corrosion does not occur and solid particles do not appear on the surface. The surface roughness of the mild steel appears lower with addition of the inhibitor than that without addition. The roughness is found to be more uniform after treatment with acidic solution which contains inhibitor.

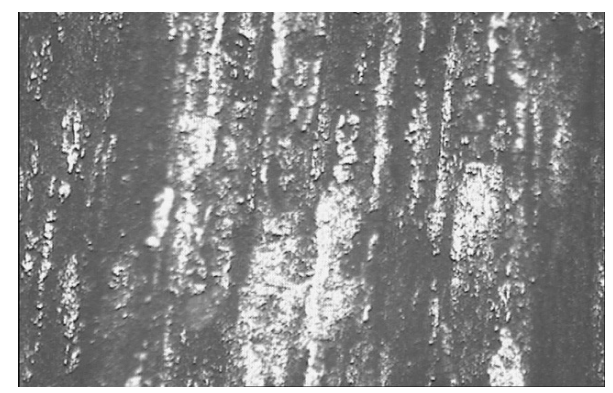

Figure 4 (a): -Mild steel sample blank kept in $1 \mathrm{M} \mathrm{HCl}$ for 24 hours at $35^{\circ} \mathrm{C}$.

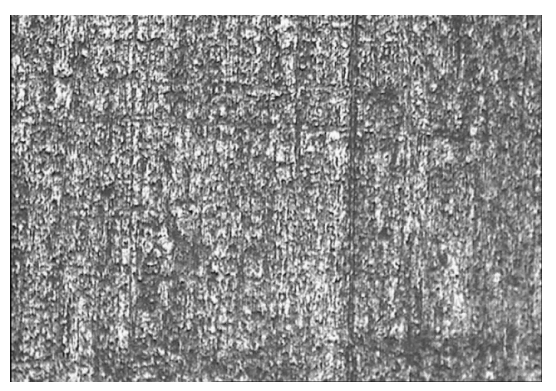

Figure 4 (b) Mild steel sample kept in $1 \mathrm{M}$ $\mathrm{HCl}$ for 24 hours with $250 \mathrm{ppm}$ SLS at $35^{\circ} \mathrm{C}$

Corrosion inhibition of mild steel in acidic solution by SLS can be explained on the basis of adsorption. SLS inhibit the corrosion by controlling both anodic and cathodic reactions but predominantly anodic reaction is controlled.

\section{Conclusions}

1. Sodium lauryl sulfate (SLS) inhibited mild steel corrosion in $1 \mathrm{M} \mathrm{HCl}$ solutions.

2. Corrosion inhibition of mild steel in $1 \mathrm{M} \mathrm{HCl}$ solutions by SLS is under anodic control.

3. Inhibition efficiency of SLS increases with increase in concentration.

4. The weight loss measurements are in good agreement with electrochemical method 
5. The micrographs analysis has shown that inhibition of corrosion by SLS is due to formation of layer on the mild steel surface.

\section{References}

1. Raval D A and Mannari V M, Res Ind, 1994, 39,94,

2. Keera S T, Br Corros J, 2001, $36,150$.

3. Keera S T and Omar A M A, Mans Sci. Bull, 1996, 23, 11.

4. Gomma G K, Material Chem. Phys, 1998, 55, 235.

5. Al-Mayout AM, Al-Amury AK and Al-Suhybani, Corros Sci, 2001, 57,614.

6. Quaraishi M A and Sharma N K, Indian Journal of Chemical Technology, 2005,12, 98.

7. Achouri M El, Infante M R, Izquierdo F, Kertit S, Couttoya H M and Nciri B, Corros Sci, 2001, 43, 19.

8. Chababe D, Ait Chikh Z, Hajjaji N, Srhivi A and Zucchi F, Corros Sci., 2003, 45,309.

9. Hajjaji N, Rico I, Srhivi A, Lattes A, Sonjiaoni M. and Ben Bachir A, Corros Sci . 1993, 49(4), 326.

10. Bastidas J M, Polo J L, Cano E, J. Appl. Electrochem, 2000, 30, 1173.

11. Hammer N E, in: Nathan C.C. Ed, Corrosion Inhibitors, Nace Houston, Texas USA, 1973,1.

12. Ait Chikh Z, Chababe D, Dermaj A, Hajjaji N, Srhivi A, Mantemor M F, Ferraria M G S and Bastos A C, Corros Sci, 2005, 47,447. 


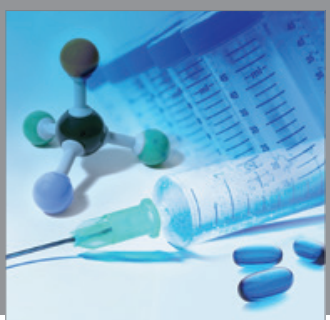

International Journal of

Medicinal Chemistry

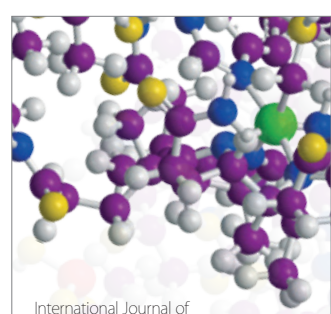

Carbohydrate Chemistry

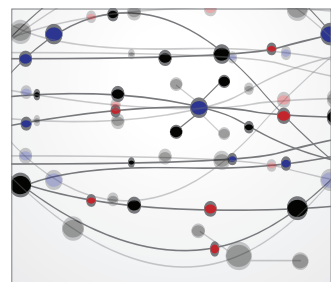

The Scientific World Journal
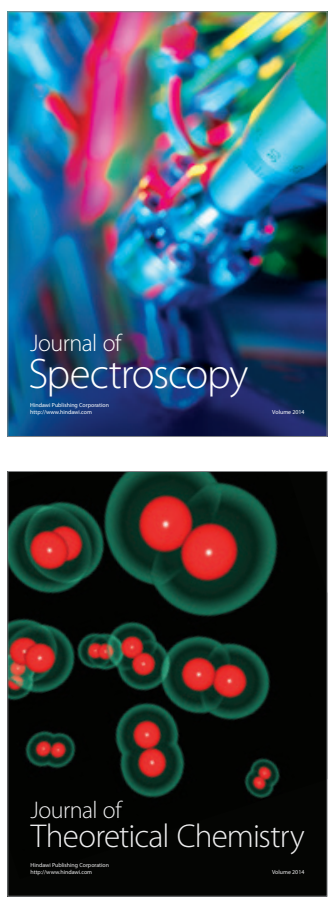
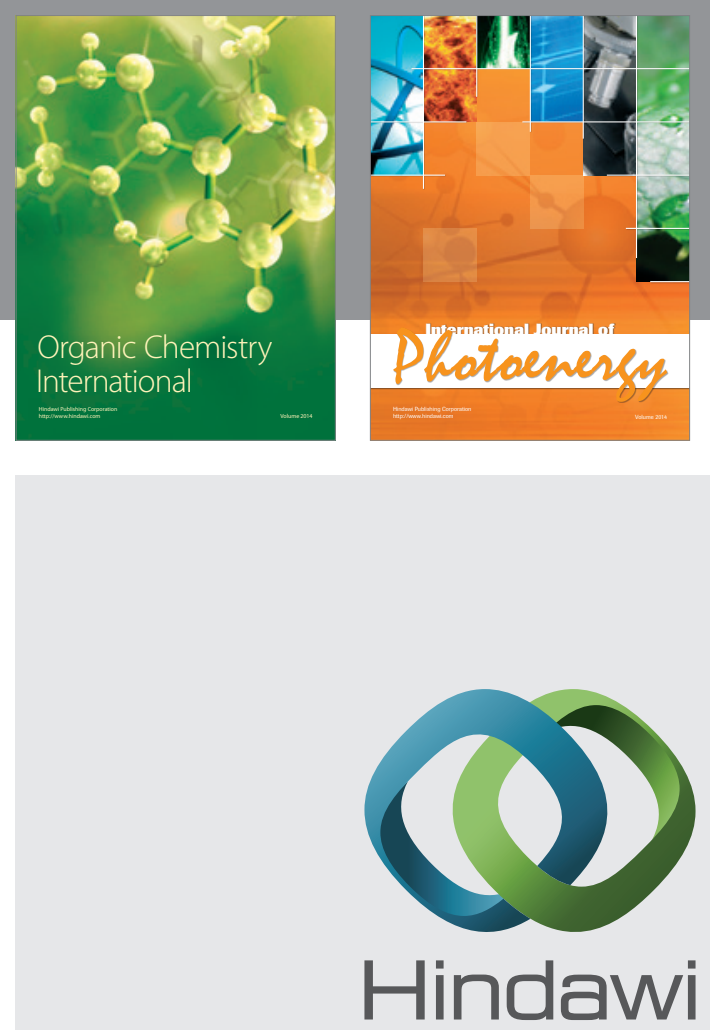

Submit your manuscripts at

http://www.hindawi.com
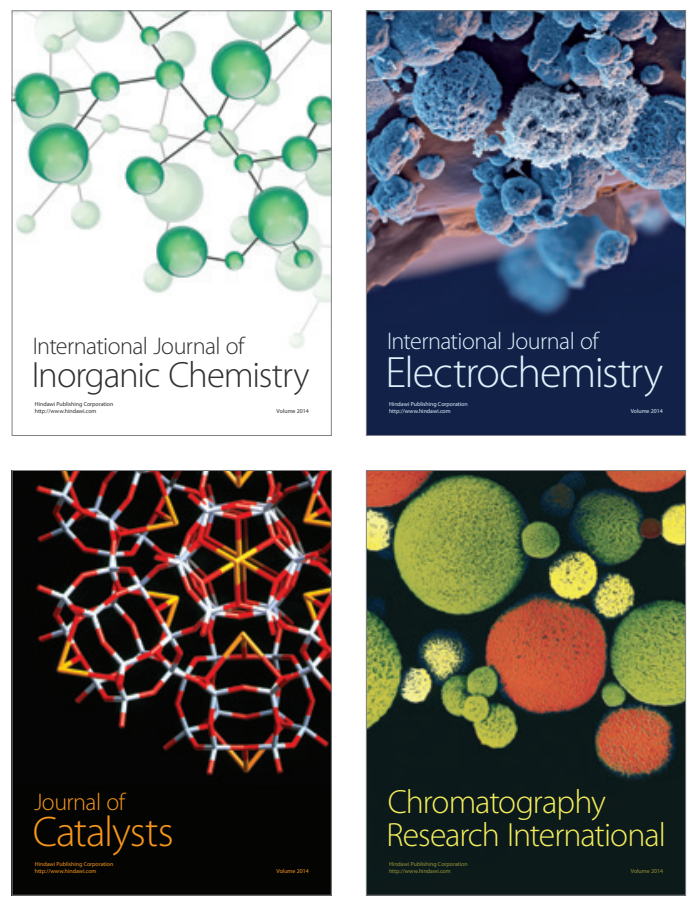
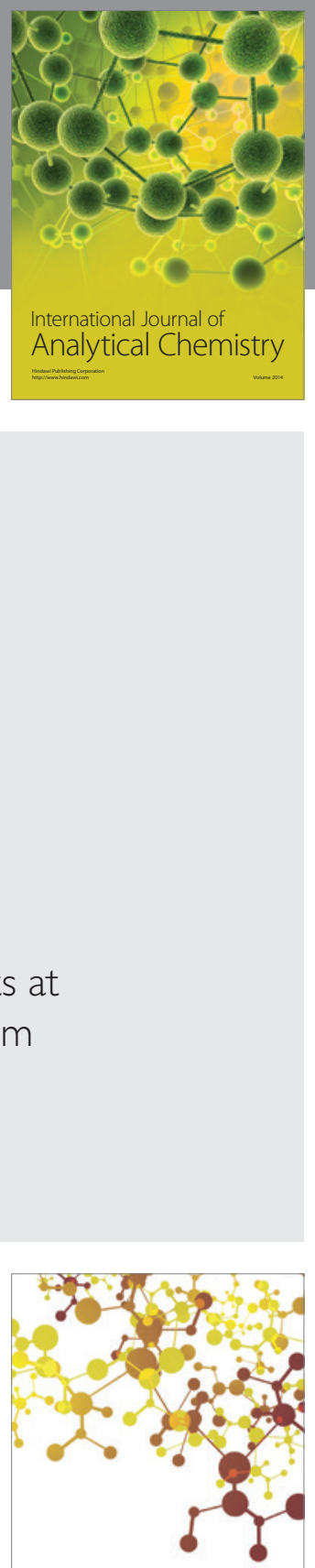

Journal of

Applied Chemistry
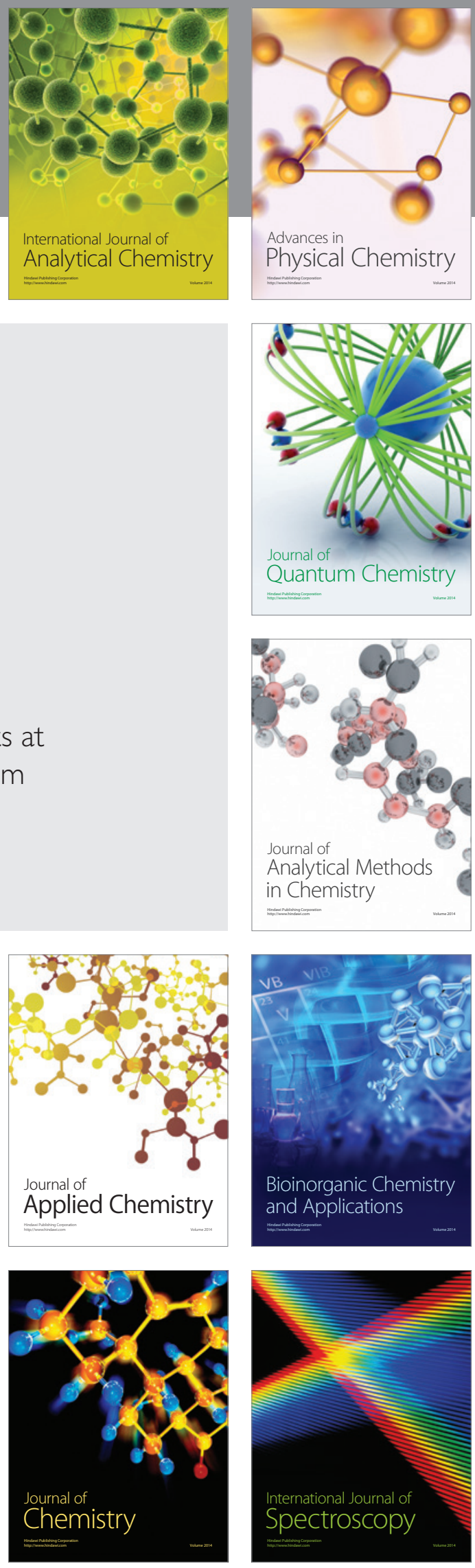